\title{
Endothelial function testing and cardiovascular disease: focus on peripheral arterial tonometry
}

\author{
This article was published in the following Dove Press journal: \\ Vascular Health and Risk Management \\ 26 September 2014 \\ Number of times this article has been viewed
}

\section{Rosa Maria Bruno' \\ Tommaso Gori ${ }^{2}$ \\ Lorenzo Ghiadoni ${ }^{3}$ \\ 'Institute of Clinical Physiology CNR, Pisa, Italy; ${ }^{2}$ Department of Medicine II, University Medical Center of the Johannes Gutenberg-University Mainz, Mainz, Germany; ${ }^{3}$ Department of Clinical and Experimental Medicine, University of Pisa, Pisa, Italy}

Correspondence: Rosa Maria Bruno Institute of Clinical Physiology CNR, Via Moruzzi I, 56I25 Pisa, Italy

Tel +390503I5 2377

Fax +39050315 2355

Email rosam.bruno@gmail.com

\begin{abstract}
During recent decades, a number of methods have been developed to assess endothelial function, contributing to a better understanding of the pathophysiology of cardiovascular disease. Recently, the advent of noninvasive, reproducible techniques for assessment of endothelial function has opened novel possibilities of application in the clinical setting. Peripheral arterial tonometry is a relatively novel, user-friendly technique measuring finger pulse volume amplitude changes induced by reactive hyperemia following 5 minutes of ischemia in the upper limb. Current evidence indicates that this technique has the potential to significantly impact the field of cardiovascular research and prevention of cardiovascular disease. However, a number of methodological, pathophysiological, and clinical aspects still need to be clarified before widespread application of this promising technique. This review focuses on the current knowledge and future perspectives of peripheral arterial tonometry, in comparison with the most widely used noninvasive technique, ie, flow-mediated dilation.
\end{abstract}

Keywords: endothelium, reactive hyperemia, microcirculation

\section{Introduction}

The atherosclerotic process is the main mechanism leading to cardiovascular disease, which is the leading cause of mortality and morbidity worldwide. ${ }^{1}$ For this reason, the pathophysiology of atherosclerosis, particularly the very early phases, including endothelial dysfunction, has attracted growing attention in recent decades.

In healthy individuals, the endothelium exerts a protective effect on the vasculature by the production of nitric oxide (NO), which derives from the transformation of L-arginine into citrulline by the constitutive endothelial enzyme NO synthase. NO is produced under the stimulus of agonists (acetylcholine, bradykinin, and others) acting on specific endothelial receptors, and of mechanical forces, namely shear stress. ${ }^{2,3} \mathrm{In}$ pathological conditions, both endothelium-derived contracting factors (eg, thromboxane $\mathrm{A} 2$ and prostaglandin $\mathrm{H} 2$ ), which counteract the relaxing activity of $\mathrm{NO}$, and reactive oxygen species, which cause breakdown of $\mathrm{NO}$ and reduce its availability, ${ }^{3}$ determine a proatherosclerotic change in vascular phenotype, causing vasoconstriction and promoting platelet aggregation, vascular smooth muscle cell proliferation and migration, and monocyte adhesion. ${ }^{4}$

In recent years, different methods have been developed to assess endothelial function, contributing to a better understanding of the pathophysiology of cardiovascular disease. Recently, the advent of noninvasive, reproducible techniques for assessment of endothelial function has opened novel possibilities of application in the clinical setting, including the ability to detect atherosclerosis in an early stage, to improve stratification 
of cardiovascular risk, to estimate future risk of cardiovascular events, and to evaluate the anti-atherosclerotic effect of new interventions. ${ }^{5-7}$ Although measurements of endothelial function are not yet recommended by guidelines for cardiovascular prevention, ${ }^{8,9}$ recent studies using noninvasive approaches and improved standardization might lead to assessment of endothelial function becoming a routine evaluation for the prevention of cardiovascular disease. This review focuses on physiology, methodology, current applications, and future perspectives with regard to peripheral arterial tonometry (PAT), in comparison with the most widely used noninvasive technique, ie, so-called flow-mediated dilation (FMD).

\section{Overview of endothelial function testing}

A number of techniques have been developed to assess endothelial function in humans, including biochemical markers, genetic markers, and vascular reactivity tests. ${ }^{6}$ As already mentioned, endothelial dysfunction is the earliest stage of the atherosclerotic process, characterized mainly by reduced NO availability. In this early stage, no structural lesions are present. Further, NO has an extremely short half-life, making its direct evaluation very difficult. Thus, vascular reactivity tests have become the most common and reliable methods for assessment of endothelial function. Mirroring endothelial physiology, in vascular reactivity tests nonpharmacological or pharmacological stimuli for NO release, and thus for endothelium-dependent vasodilatation, are administered. The absence or reduction of physiological endothelium-dependent dilatation is then considered an index of endothelial dysfunction.

The first demonstration of endothelial dysfunction dates back to $1986,{ }^{10}$ by infusion of acetylcholine in atherosclerotic coronary arteries. Evaluation of coronary epicardial and microvascular function has the advantage of being able to measure the endothelial response directly in this clinically important vascular bed, but of course is not widely applicable, being an invasive study requiring cannulation of the coronary arteries and intracoronary drug infusion.

Plethysmography of the forearm circulation is a semiinvasive technique and requires arterial cannulation, introduced for exploration of microvascular pathophysiological mechanisms in health and disease. ${ }^{11}$ Changes in forearm blood flow are measured by venous plethysmography in both arms before and after infusion of vasoactive substances into the brachial artery, with virtually no systemic effects.

Later on, less invasive techniques were developed, investigating peripheral regions such as the upper limbs as a surrogate for the coronary arteries. ${ }^{6}$ The most widely used technique is FMD. This is a noninvasive, ultrasoundbased method, introduced in $1992 .{ }^{12}$ FMD is the percent age of change in brachial artery diameter in response to increased shear stress induced by reactive hyperemia. To measure FMD, a sphygmomanometer cuff placed around the forearm distal to the brachial artery is inflated and then released 5 minutes later. FMD has been studied widely in clinical research because it enables serial evaluation of young subjects, including children. ${ }^{12}$ Moreover, it has been demonstrated that FMD is sustained by NO, since it is inhibited by the intra-arterial administration of NO synthase inhibitors in invasive studies. ${ }^{13,14}$ Impaired FMD has been demonstrated in the presence of traditional cardiovascular risk factors and has been correlated with Framingham risk score. ${ }^{15}$ Several studies have shown that impaired FMD is an early indicator of atherosclerotic damage and is associated with target organ damage, including increased carotid intima media thickness ${ }^{16-18}$ and left ventricular hypertrophy. ${ }^{19}$ More importantly, it has been associated with major cardiovascular events not only in patients with atherosclerotic coronary disease or characterized as high-risk, ${ }^{20}$ but also in low-risk populations. ${ }^{21}$ Finally, several studies have demonstrated that FMD can be improved by modification of risk factors and use of drugs known to reduce cardiovascular risk in a much shorter time (a few months) than that required for other vascular endpoints, such as carotid intima media thickness, offering a potential reason for being included in clinical trials as a surrogate end point. ${ }^{22-25}$ Despite this growing evidence, large clinical trials are needed to demonstrate conclusively whether reversal of impaired FMD might herald a better prognosis in patients both with cardiovascular risk factors or with established cardiovascular disease. Further, several methodological challenges might limit the widespread application of this method in clinical studies and in daily practice. ${ }^{6,25-28}$ For this reason, simpler noninvasive techniques, such as PAT, might represent an appealing alternative.

\section{Peripheral arterial tonometry Methodological aspects}

In the recent years, measurement of endothelial function using PAT has gained increasing attention. ${ }^{29}$ PAT technology was originally developed for measurement of the vascular changes associated with arousal during sleep ${ }^{30}$ and was then applied to vascular reactivity tests. ${ }^{31}$

PAT methodology will be described in direct comparison with FMD, with the main similarities and differences summarized in Table 1. Endothelial function testing using 
Table I Comparison between PAT and FMD

\begin{tabular}{|c|c|c|}
\hline & PAT & FMD \\
\hline District examined & $\begin{array}{l}\text { Finger micro/ } \\
\text { macrocirculation }\end{array}$ & Brachial artery \\
\hline Stimulus & $\begin{array}{l}\text { Upper limb } \\
\text { ischemia }\end{array}$ & $\begin{array}{l}\text { Upper limb } \\
\text { ischemia }\end{array}$ \\
\hline Endpoint variable & $\begin{array}{l}\text { Pulse volume } \\
\text { amplitude }\end{array}$ & $\begin{array}{l}\text { Brachial artery } \\
\text { diameter }\end{array}$ \\
\hline Noninvasiveness & +++ & +++ \\
\hline Easiness & +++ & ++ \\
\hline Operator independency & +++ & ++ \\
\hline Reproducibility & ++ & +++ \\
\hline Automated analysis & +++ & +++ \\
\hline $\begin{array}{l}\text { Endothelium-independent } \\
\text { vasodilation assessment }\end{array}$ & - & ++ \\
\hline NO dependency & ++ & +++ \\
\hline Correlation with CV factors & +++ & +++ \\
\hline Predictive value for $\mathrm{CV}$ events & +++ & +++ \\
\hline Improvement with treatment & + & +++ \\
\hline $\begin{array}{l}\text { Predictive value for changes } \\
\text { over time }\end{array}$ & - & ++ \\
\hline
\end{tabular}

Abbreviations: PAT, peripheral arterial tonometry; FMD, flow-mediated dilation; $\mathrm{CV}$, cardiovascular; NO, nitric oxide.

PAT is based on the same physiological mechanisms as the FMD technique, inducing transient ischemia in the upper limb as a stimulus for reactive vasodilatation. Accordingly, a pressure cuff is placed around the arm and inflated above systolic pressure after a baseline recording; the cuff is then deflated after 5 minutes to induce reactive hyperemia in one arm. Unlike with FMD, the endpoint measured is finger arterial pulse volume amplitude (PVA), instead of brachial artery diameter (Figure 1). A main advantage of the system is that the contralateral arm serves as an internal control. The ratio between hyperemic and baseline PVA (PAT ratio) is normalized for the same ratio in the contralateral arm, thus obtaining the reactive hyperemia index (RHI), or its natural logarithm $(\ln \mathrm{RHI}){ }^{29}$

Reproducibility is a crucial issue when vascular reactivity tests are compared. In the past, technical complexity and low reproducibility were acknowledged as the main limitations of the FMD technique. For example, in the Multi-Ethnic Study of Atherosclerosis (MESA) study, the intraclass coefficient for FMD was 0.54 , probably explaining the lack of predictive value demonstrated for FMD in this study. ${ }^{32}$ However, standardization of the technique allowed excellent reproducibility of FMD to be obtained. The coefficient of variation was $9.9 \%$ and $12.9 \%$ for two repeated measurements one hour and one month apart, respectively, in a cohort of 130 volunteers, ${ }^{33}$ while in larger high-risk populations, it was $18.3 \%$ for two repeated measurements 3 months apart. ${ }^{34}$

At variance with FMD, the PAT technique is operatorindependent, and the pulse amplitude recordings are digitized and analyzed by an automated, proprietary algorithm. PAT operators require a very short training period and do not need specific certification. Surprisingly, this seems to confer no advantage in terms of reproducibility in comparison with FMD, at least when the latter is performed in agreement with standardized protocols. In a small study directly comparing the two techniques in 18 patients with coronary artery disease, the within-day variability was lower for FMD measurements than for PAT measurements (10\% versus $18 \%$,

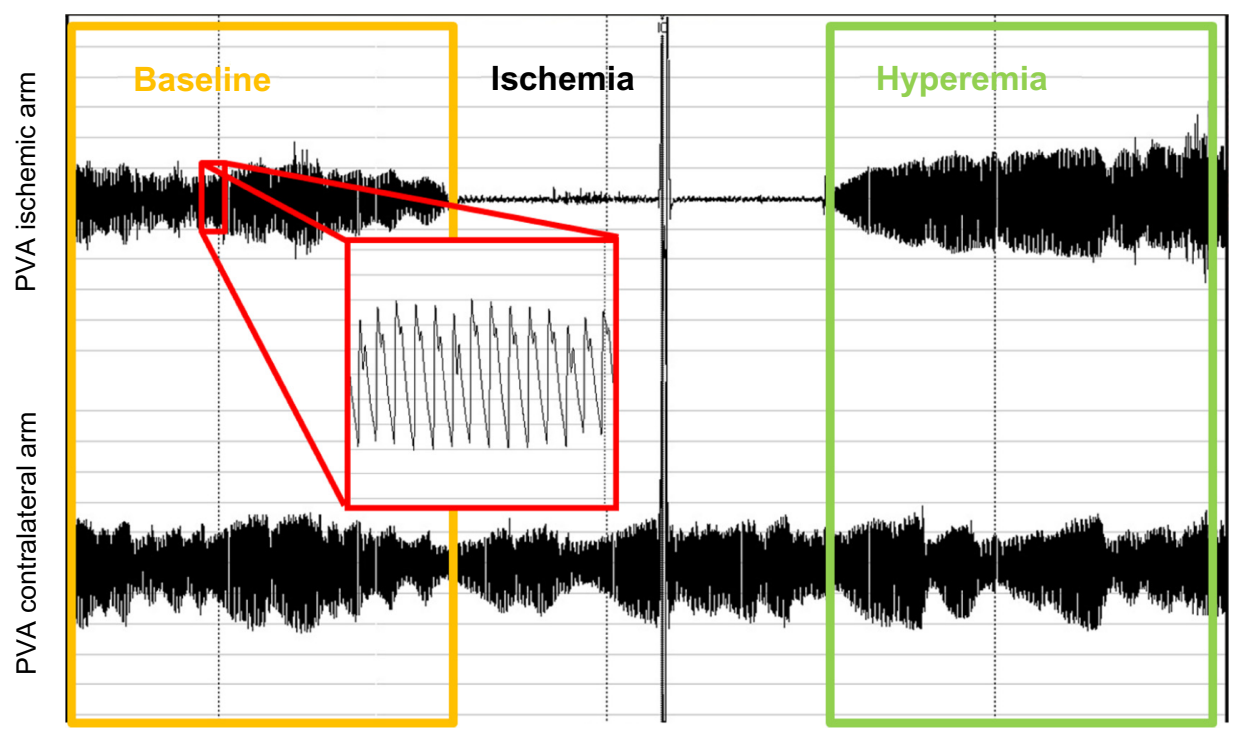

Figure I Recording from a peripheral arterial tonometry test. The baseline period is highlighted in yellow box, and the hyperemic period is highlighted in green. A magnified detail of PVA is highlighted in red.

Abbreviation: PVA, pulse volume amplitude. 
respectively; $P<0.05$ ), while the between-day variability was similar. ${ }^{35}$ Reproducibility studies performed in larger cohorts found coefficients of variation for within-day variability ( $0.5-4$ hours) ranging from $15 \%$ to $22 \%$, with lower interday reproducibility ${ }^{36,37}$ (Table 1).

Finally, the classical methodology in the vascular reactivity test includes evaluation of endothelium-independent vasodilation by administration of low-dose, sublingual nitrates in order to ascertain vascular smooth muscle function. ${ }^{38,39}$ To date, this test has not been included in PAT protocols, since only preliminary information obtained with a relatively high nitrate dose suggests a different time course for dilatation in the brachial artery and PVA. ${ }^{40}$ Nevertheless, at present, assessment of endothelium-independent vasodilation with the PAT technique is not possible, since results are provided changes in PAT signal as ratio an arm to contralateral one, whereas systemic administration of nitrates would provide a similar changes in the two arms leading to a ratio of approximately 1 , independently of the clinical condition.

\section{Pathophysiological aspects}

There is growing evidence that PAT can predict cardiovascular events, as discussed in the following chapter. For this reason, this test is currently reimbursed for patients with cardiovascular disease in the USA. However, its pathophysiological basis has not been extensively clarified as yet.

Indeed, PVA is likely to be a proxy for arterial distensibility and venous capacitance of the vascular digital district, so its changes conceivably represent vascular function. However, the digital vasculature is anatomically complex, consisting of a dual circulation of nutritive vessels and arteriovenous anastomoses. Resting vascular tone in the latter is primarily regulated by the sympathetic nervous system, while NO only plays a marginal role. ${ }^{41}$ In line with this observation, pharmacological inhibition of NO synthesis reduced PAT reactive hyperemia after upper cuff occlusion by less than $50 \%,{ }^{42}$ whereas the FMD response in the brachial artery with lower cuff occlusion is almost completely inhibited by blockade of NO. ${ }^{43,44}$ Thus, augmentation of PVA after reactive hyperemia is a complex response, involving mechanisms that are both related and unrelated to the endothelium, with a limited specificity as a measure of $\mathrm{NO}$ availability. ${ }^{42}$

Although a number of reports with conflicting results regarding the correlation between FMD and PAT have been published, the two largest cohorts from the general population ever studied using both techniques, ie, the Framingham heart study ${ }^{45}$ and the Gutenberg heart study, ${ }^{46}$ recruiting about 5,000 individuals each, both found that a modest correlation exists between FMD and PAT, which was weakened by adjustment for confounders. A smaller study, performing simultaneous PAT and brachial artery ultrasound measures with forearm occlusion in a cohort of 99 individuals with coronary artery disease (CAD) and 44 healthy volunteers, ${ }^{47}$ also investigated the correlation with measures of reactive hyperemia. Again, RHI was not correlated with FMD either in patients or in healthy volunteers, while a significant correlation was found with reactive hyperemiainduced increases in brachial artery flow velocity. Further, even at baseline, PVA and flow velocity were significantly associated independent of confounders. ${ }^{47}$

There is growing evidence that measures such as blood flow or shear stress response after cuff deflation during FMD testing, which are markers of microvascular function rather than of NO availability, are independently associated with cardiovascular events, ${ }^{48,49}$ although conflicting results exist. $^{50}$ In the Firefighters and Their Endothelium (FATE) study, which included 1,574 middle-aged apparently healthy men at low cardiovascular risk, hyperemic velocity in the brachial artery, but not FMD, was associated with future clinical events, independently of Framingham risk score. ${ }^{51}$ However, FMD of the brachial artery performed with upper arm occlusion is inhibited by pharmacological NO blockade by about $40 \%,{ }^{44}$ which is comparable with that of shown in studies with PAT, ${ }^{42}$ whereas the FMD response in the brachial artery with lower cuff occlusion is almost completely inhibited by blockade of NO. ${ }^{44}$ Nevertheless, a meta-analysis of available studies suggested that FMD obtained with upper cuff occlusion has the same prognostic significance that FMD performed with lower cuff occlusion. ${ }^{43}$

\section{Clinical significance}

Several lines of evidence reinforce the clinical relevance of endothelial function measured with the PAT technique. First, reductions in PAT measurements are correlated with coronary endothelial dysfunction. ${ }^{52}$ Further, the PAT ratio is reduced in patients with both with cardiovascular risk factors or with established cardiovascular disease. In 89 patients with suspected CAD undergoing exercise myocardial perfusion imaging, PAT, and FMD measures, the PAT ratio, as well as FMD, was reduced with increasing numbers of cardiovascular risk factors. Further, both measures were significantly lower in the presence of a positive provocative test. ${ }^{31}$ Interestingly, despite these similarities, the two measures seem to be differentially influenced by conventional cardiovascular risk factors. In the Framingham heart study, ${ }^{45}$ reduced FMD was associated with increasing age, higher 
systolic blood pressure, and higher body mass index (BMI), while a reduced PAT ratio was associated with higher BMI, lower systolic blood pressure, lipid profile and medications, diabetes, and smoking. Reduced hyperemic flow velocity was instead correlated with age, female gender, increased systolic blood pressure and decreased diastolic blood pressure, and a history of cardiovascular disease. Also, in the Gutenberg heart study, ${ }^{46}$ determinants of FMD were BMI, higher blood pressure, and lipid profile, while determinants of the PAT ratio were lower blood pressure, lipid profile, and BMI, and also included fasting glucose and prevalent cardiovascular disease. Thus, despite the use of different sites of cuff occlusion (forearm versus upper arm), and different statistical approaches, the two studies showed substantially similar results and concluded that the two measures possibly represent "two sides of the same coin".

Thus far, few prospective studies (summarized in Table 2) have investigated the possible predictive role of PAT measures for cardiovascular events. In a cohort of 270 patients referred to a cardiology unit for chest pain but with negative stress testing or normal coronary angiography, an lnRHI of $<0.40$ was an independent predictor of cardiovascular events after a 7-year follow-up. ${ }^{53}$ Two prospective studies enrolled patients with heart failure and preserved left ventricular ejection, demonstrating that RHI can predict the onset of cardiovascular events and improve the C-statistic when compared with conventional risk stratification, ${ }^{54}$ and that $\ln \mathrm{RHI}$ can predict heart failure-related adverse events. ${ }^{55}$ Similar findings were obtained in 528 patients at high risk, in whom RHI improved the net reclassification index and C-statistic when added to Framingham risk score, brain natriuretic peptide, and coronary angiography score.$^{56}$ Finally, an independent predictive role for cardiovascular events was recently demonstrated in a cohort of patients with chronic kidney disease. ${ }^{57}$

Thus, we can conclude that PAT measures have a significant predictive role for cardiovascular events in high-risk populations. Future studies should ascertain their role in low-risk patients and in the general population.

On the other hand, while a number of studies assessed the cross-sectional relationship between PAT, lifestyle and risk factors, ${ }^{45,46,58}$ only few studies are available for assessing the reversibility of impaired PAT measures. Nonpharmacological and pharmacological treatments were used to test the effects of antioxidant-rich foods, ${ }^{59,60}$ physical exercise, ${ }^{61}$ and antiinflammatory drugs. ${ }^{62}$ Interestingly, treatments able to improve FMD, such as angiotensin receptor blockers, ${ }^{63}$ failed to improve RHI, ${ }^{64}$ so the question of the clinical interpretation of treatment-induced PAT chances and the use of this test as a surrogate endpoint in clinical trials, is still open. Further, at variance with $\mathrm{FMD},{ }^{65,66}$ the predictive role of changes in PAT over time is still unknown.

\section{Limitations and future perspectives}

A number of issues need to be addressed in order to define the role of this new and promising technique in clinical research and clinical practice. With regard to methodology, the reasons

Table 2 Prospective studies investigating the predictive role of peripheral arterial tonometry

\begin{tabular}{|c|c|c|c|c|c|}
\hline Study & Population & $\begin{array}{l}\text { Follow-up } \\
\text { duration }\end{array}$ & Clinical endpoint & $\begin{array}{l}\text { Number } \\
\text { of events }\end{array}$ & Results \\
\hline $\begin{array}{l}\text { Rubinstein } \\
\text { et } \mathrm{al}^{53}\end{array}$ & $\begin{array}{l}270 \text { patients with } \\
\text { suspected CAD }\end{array}$ & 5.8 years & $\begin{array}{l}\mathrm{CV} \text { death, nonfatal } \mathrm{MI} \text {, coronary } \\
\text { revascularization or } \mathrm{CV} \text { hospitalization }\end{array}$ & 86 & $\begin{array}{l}\text { Low RHI }(<0.4) \\
\text { Adj HR I.79 (I.I6-2.76), P=0.008 }\end{array}$ \\
\hline $\begin{array}{l}\text { Akiyama } \\
\text { et } \text { al }^{54}\end{array}$ & $\begin{array}{l}32 \text { I patients with } \\
\text { HFPEF }\end{array}$ & 20 months & $\begin{array}{l}\text { CV death, nonfatal MI, unstable } \\
\text { angina pectoris, nonfatal ischemic } \\
\text { stroke, coronary revascularization, } \\
\text { hospitalization for HF }\end{array}$ & 59 & $\begin{array}{l}0.1 \text { increase in RHI } \\
\text { Adj HR } 0.80(0.67-0.94), P=0.007 \\
\text { Improvement in C-statistics }\end{array}$ \\
\hline $\begin{array}{l}\text { Matsue } \\
\text { et } \mathrm{al}^{55}\end{array}$ & $\begin{array}{l}\text { I59 patients with } \\
\text { HFPEF }\end{array}$ & 300 days & HF-related death, hospitalization for HF & 32 & $\begin{array}{l}\text { For } 0.1 \text { increase in InRHI } \\
\text { HR } 0.56(0.39-0.80)\end{array}$ \\
\hline $\begin{array}{l}\text { Matsuzawa } \\
\text { et } \mathrm{al}^{56}\end{array}$ & $\begin{array}{l}528 \text { patients with } \\
\text { suspected } C A D\end{array}$ & 2.8 years & $\begin{array}{l}\text { CV death, nonfatal MI, unstable angina, } \\
\text { nonfatal ischemic stroke, coronary } \\
\text { revascularization, hospitalization for HF, } \\
\text { nonfatal aortic disease, and peripheral } \\
\text { arterial disease }\end{array}$ & 105 & $\begin{array}{l}0 . \mathrm{I} \text { increase in RHI } \\
\text { Adj HR } 0.76(0.67-0.86), P<0.000 \mathrm{I} \text {. } \\
\text { Improvement in C-statistic and net } \\
\text { reclassification index }\end{array}$ \\
\hline $\begin{array}{l}\text { Hirata } \\
\text { et } \mathrm{al}^{57}\end{array}$ & $\begin{array}{l}383 \text { patients with } \\
\text { chronic kidney } \\
\text { disease }\end{array}$ & 30 months & $\begin{array}{l}\text { CV death, non-fatal MI, unstable angina, } \\
\text { nonfatal ischemic stroke, coronary } \\
\text { revascularization, hospitalization for HF }\end{array}$ & 90 & $\begin{array}{l}\text { Low } \mathrm{RHI}(<0.525) \\
\text { HR } 2.70(\mathrm{I} .62-4.5 \mathrm{I}), P=0.00 \mathrm{I} \\
\text { Improvement in C-statistic and net } \\
\text { reclassification index }\end{array}$ \\
\hline
\end{tabular}

Abbreviations: CAD, coronary artery disease; CV, cardiovascular; MI, myocardial infarction; HF, heart failure; HFPEF, heart failure with preserved ejection fraction; $\mathrm{RHI}$, reactive hyperemia index; adj, adjusted; HR, hazard ratio. 
for suboptimal reproducibility should be investigated, as well as an improvement strategy. Further, it has to be ascertained whether PAT technology is also feasible for assessment of endothelium-independent vasodilation and by which approach. Future studies should explore the pathophysiology of PAT, including the anatomical and hemodynamic determinants of PVA and changes therein. In particular, whether RHI represents a measure of endothelial function rather than being a more general indicator of microvascular function should be clarified.

From the clinical point of view, the predictive role of PAT measures in the general population, as well as the predictive role of changes in PAT over time should be investigated. Finally, further studies are required to establish whether improvement in RHI after therapeutic interventions might be used as a surrogate endpoint for cardiovascular disease.

\section{Conclusion}

The current evidence indicates that PAT has the potential to significantly impact the field of cardiovascular research and prevention of cardiovascular disease. However, a number of methodological, pathophysiological, and clinical aspects still need to be clarified before application of this promising, user-friendly technique. In particular, its added or complementary value when compared with more established techniques should be defined before its use in the cardiovascular research setting. Further, more solid evidence is required before it can be used extensively in the clinical setting.

\section{Disclosure}

LG is one of the founders of Quipu s.r.1. The other authors report no conflicts of interest in this work.

\section{References}

1. Ezzati M, Lopez AD, Rodgers A, Vander Hoorn S, Murray CJ. Selected major risk factors and global and regional burden of disease. Lancet. 2002;360(9343):1347-1360.

2. Furchgott RF, Zawadzki JV. The obligatory role of endothelial cells in the relaxation of arterial smooth muscle by acetylcholine. Nature. 1980;288(5789):373-376.

3. Luscher TF, Barton M. Biology of the endothelium. Clin Cardiol. 1997;20(11 Suppl 2):II-3-10.

4. Ross R. Atherosclerosis - an inflammatory disease. $N$ Engl J Med. 1999;340(2):115-126.

5. Bianchini E, Giannarelli C, Bruno RM, et al. Functional and structural alterations of large arteries: methodological issues. Curr Pharm Des. 2013;19(13):2390-2400.

6. Deanfield J, Donald A, Ferri C, et al. Endothelial function and dysfunction. Part I: Methodological issues for assessment in the different vascular beds: a statement by the Working Group on Endothelin and Endothelial Factors of the European Society of Hypertension. J Hypertens. 2005;23(1):7-17.
7. Deanfield JE, Halcox JP, Rabelink TJ. Endothelial function and dysfunction: testing and clinical relevance. Circulation. 2007;115(10): $1285-1295$.

8. Graham I, Atar D, Borch-Johnsen K, et al. European guidelines on cardiovascular disease prevention in clinical practice: full text. Fourth Joint Task Force of the European Society of Cardiology and other societies on cardiovascular disease prevention in clinical practice (constituted by representatives of nine societies and by invited experts). Eur J Cardiovasc Prev Rehabil. 2007;14 Suppl 2: S1-S113.

9. Greenland P, Alpert JS, Beller GA, et al. 2010 ACCF/AHA guideline for assessment of cardiovascular risk in asymptomatic adults: a report of the American College of Cardiology Foundation/American Heart Association Task Force on Practice Guidelines. J Am Coll Cardiol. 2010;56(25):e50-e103.

10. Ludmer PL, Selwyn AP, Shook TL, et al. Paradoxical vasoconstriction induced by acetylcholine in atherosclerotic coronary arteries. $N$ Engl $J$ Med. 1986;315(17):1046-1051.

11. Taddei S, Virdis A, Ghiadoni L, Magagna A, Salvetti A. Vitamin $\mathrm{C}$ improves endothelium-dependent vasodilation by restoring nitric oxide activity in essential hypertension. Circulation. 1998;97(22): 2222-2229.

12. Celermajer DS, Sorensen KE, Gooch VM, et al. Non-invasive detection of endothelial dysfunction in children and adults at risk of atherosclerosis. Lancet. 1992;340(8828):1111-1115.

13. Joannides R, Haefeli WE, Linder L, et al. Nitric oxide is responsible for flow-dependent dilatation of human peripheral conduit arteries in vivo. Circulation. 1995;91(5):1314-1319.

14. Ghiadoni L, Versari D, Magagna A, et al. Ramipril dose-dependently increases nitric oxide availability in the radial artery of essential hypertension patients. $J$ Hypertens. 2007;25(2):361-366.

15. Benjamin EJ, Larson, MG, Keyes MJ, et al. Clinical correlates and heritability of flow-mediated dilation in the community: The Framingham Heart Study. Circulation. 2004;109(5):613-619.

16. Juonala M, Viikari JS, Laitinen T, et al. Interrelations between brachial endothelial function and carotid intima-media thickness in young adults - The Cardiovascular Risk in Young Finns Study. Circulation. 2004;110(18):2918-2923.

17. Rundek T, Hundle R, Ratchford E, et al. Endothelial dysfunction is associated with carotid plaque: a cross-sectional study from the population based Northern Manhattan Study. BMC Cardiovasc Disord. 2006;6:35.

18. Halcox JP, Donald AE, Ellins E, et al. Endothelial function predicts progression of carotid intima-media thickness. Circulation. 2009;119(7):1005-1012.

19. Ercan E, Tengiz I, Ercan HE, Nalbantgil I. Left ventricular hypertrophy and endothelial functions in patients with essential hypertension. Coron Artery Dis. 2003;14(8):541-544.

20. Lerman A, Zeiher AM. Endothelial function: cardiac events. Circulation. 2005;111(3):363-368.

21. Inaba Y, Chen JA, Bergmann SR. Prediction of future cardiovascular outcomes by flow-mediated vasodilatation of brachial artery: a metaanalysis. Int J Cardiovasc Imaging. 2010;26(6):631-640.

22. Ghiadoni L, Magagna A, Versari D, et al. Different effect of antihypertensive drugs on conduit artery endothelial function. Hypertension. 2003;41(6):1281-1286.

23. Charakida M, Masi S, Loukogeorgakis SP, Deanfield JE. The role of flow-mediated dilatation in the evaluation and development of antiatherosclerotic drugs. Curr Opin Lipidol. 2009;20(6): 460-466.

24. Plantinga Y, Ghiadoni L, Magagna A, et al. Supplementation with vitamins $\mathrm{C}$ and $\mathrm{E}$ improves arterial stiffness and endothelial function in essential hypertensive patients. Am J Hypertens. 2007;20(4): 392-397.

25. Charakida M, Masi S, Luscher TF, Kastelein JJ, Deanfield JE. Assessment of atherosclerosis: the role of flow-mediated dilatation. Eur Heart J. 2010;31(23):2854-2861. 
26. Corretti MC, Anderson TJ, Benjamin EJ, et al. Guidelines for the ultrasound assessment of endothelial-dependent flow-mediated vasodilation of the brachial artery: a report of the International Brachial Artery Reactivity Task Force. J Am Coll Cardiol. 2002;39(2):257-265.

27. Ghiadoni L, Penno G, Giannarelli C, et al. Metabolic syndrome and vascular alterations in normotensive subjects at risk of diabetes mellitus. Hypertension. 2008;51(2):440-445.

28. Thijssen DH, Black MA, Pyke KE, et al. Assessment of flow-mediated dilation in humans: a methodological and physiological guideline. Am J Physiol Heart Circ Physiol. 2011;300(1):H2-H12.

29. Reriani MK, Lerman LO, Lerman A. Endothelial function as a functional expression of cardiovascular risk factors. Biomark Med. 2010;4(3):351-360.

30. Lavie P, Shlitner A, Sheffy J, Schnall RP. Peripheral arterial tonometry: a novel and sensitive non-invasive monitor of brief arousals during sleep. Isr Med Assoc J. 2000;2(3):246-247.

31. Kuvin JT, Patel AR, Sliney KA, et al. Assessment of peripheral vascular endothelial function with finger arterial pulse wave amplitude. Am Heart J 2003;146(1):168-174.

32. Yeboah J, McClelland RL, Polonsky TS, et al. Comparison of novel risk markers for improvement in cardiovascular risk assessment in intermediate-risk individuals. JAMA. 2012;308(8):788-795.

33. Ghiadoni L, Faita F, Salvetti M, et al. Assessment of flow-mediated dilation reproducibility: a nationwide multicenter study. J Hypertens. 2012;30(7):1399-1405.

34. Charakida M, de Groot E, Loukogeorgakis SP, et al. Variability and reproducibility of flow-mediated dilatation in a multicentre clinical trial. Eur Heart J. 2013;34(45):3501-3507.

35. Onkelinx S, Cornelissen V, Goetschalckx K, Thomaes T, Verhamme P, Vanhees L. Reproducibility of different methods to measure the endothelial function. Vasc Med. 2012;17(2):79-84.

36. Brant LC, Barreto SM, Passos VM, Ribeiro AL. Reproducibility of peripheral arterial tonometry for the assessment of endothelial function in adults. J Hypertens. 2013;31(10):1984-1990.

37. Liu J, Wang J, Jin Y, Roethig HJ, Unverdorben M. Variability of peripheral arterial tonometry in the measurement of endothelial function in healthy men. Clin Cardiol. 2009;32(12):700-704.

38. Bruno RM, Ghiadoni L. Vascular smooth muscle function: defining the diabetic vascular phenotype. Diabetologia. 2013;56(10):2107-2109.

39. Ghiadoni L, Huang Y, Magagna A, Buralli S, Taddei S, Salvetti A Effect of acute blood pressure reduction on endothelial function in the brachial artery of patients with essential hypertension. J Hypertens. 2001;19(3 Pt 2):547-551.

40. McCue MC, Marlatt KL, Kelly AS, Steinberger J, Dengel DR. Evaluation of gender differences in endothelium-independent dilation using peripheral arterial tonometry. Clin Physiol Funct Imaging. 2012;32(2):94-98.

41. Coffman JD. Effects of endothelium-derived nitric oxide on skin and digital blood flow in humans. Am J Physiol. 1994;267(6 Pt 2):H2087-H2090.

42. Nohria A, Gerhard-Herman M, Creager MA, Hurley S, Mitra D, Ganz P. Role of nitric oxide in the regulation of digital pulse volume amplitude in humans. J Appl Physiol (1985). 2006;101(2):545-548.

43. Green DJ, Jones H, Thijssen D, Cable NT, Atkinson G. Flow-mediated dilation and cardiovascular event prediction: does nitric oxide matter? Hypertension. 2011;57(3):363-369.

44. Green DJ, Dawson EA, Groenewoud HM, Jones H, Thijssen DH Is flow-mediated dilation nitric oxide mediated? A meta-analysis. Hypertension. 2014;63(2):376-382.

45. Hamburg NM, Palmisano J, Larson MG, et al. Relation of brachial and digital measures of vascular function in the community: the Framingham heart study. Hypertension. 2011;57(3):390-396.

46. Schnabel RB, Schulz A, Wild PS, et al. Noninvasive vascular function measurement in the community: cross-sectional relations and comparison of methods. Circ Cardiovasc Imaging. 2011;4(4):371-380.

47. Lee CR, Bass A, Ellis K, et al. Relation between digital peripheral arterial tonometry and brachial artery ultrasound measures of vascular function in patients with coronary artery disease and in healthy volunteers. Am J Cardiol. 2012;109(5):651-657.
48. Mitchell GF, Parise H, Vita JA, et al. Local shear stress and brachial artery flow-mediated dilation: the Framingham Heart Study. Hypertension. 2004;44(2):134-139.

49. Huang AL, Silver AE, Shvenke E, et al. Predictive value of reactive hyperemia for cardiovascular events in patients with peripheral arterial disease undergoing vascular surgery. Arterioscler Thromb Vasc Biol. 2007;27(10):2113-2119.

50. Ostad MA, Wild PS, Schnorbus B, Schulz A, Munzel T, Warnholtz A. Predictive value of brachial reactive hyperemia and flow-mediated dilation in stable coronary artery disease. Clin Hemorheol Microcirc. 2014;56(3):247-257.

51. Anderson TJ, Charbonneau F, Title LM, et al. Microvascular function predicts cardiovascular events in primary prevention: long-term results from the Firefighters and Their Endothelium (FATE) study. Circulation. 2011;123(2):163-169.

52. Bonetti PO, Pumper GM, Higano ST, Holmes DR Jr, Kuvin JT, Lerman A. Noninvasive identification of patients with early coronary atherosclerosis by assessment of digital reactive hyperemia. J Am Coll Cardiol. 2004;44(11):2137-2141.

53. Rubinshtein R, Kuvin JT, Soffler M, et al. Assessment of endothelial function by non-invasive peripheral arterial tonometry predicts late cardiovascular adverse events. Eur Heart J. 2010;31(9):1142-1148.

54. Akiyama E, Sugiyama S, Matsuzawa $Y$, et al. Incremental prognostic significance of peripheral endothelial dysfunction in patients with heart failure with normal left ventricular ejection fraction. J Am Coll Cardiol. 2012;60(18):1778-1786

55. Matsue Y, Suzuki M, Nagahori W, et al. Endothelial dysfunction measured by peripheral arterial tonometry predicts prognosis in patients with heart failure with preserved ejection fraction. Int J Cardiol. 2013;168(1) 36-40.

56. Matsuzawa Y, Sugiyama S, Sumida H, et al. Peripheral endothelial function and cardiovascular events in high-risk patients. J Am Heart Assoc. 2013;2(6):e000426.

57. Hirata Y, Sugiyama S, Yamamoto E, et al. Endothelial function and cardiovascular events in chronic kidney disease. Int J Cardiol. 2014;173(3) 481-486.

58. Cioni G, Boddi M, Fatini C, et al. Peripheral-arterial tonometry for assessing endothelial function in relation to dietary habits. J Investig Med. 2013;61(5):867-871.

59. Kwak JH, Paik JK, Kim HI, et al. Dietary treatment with rice containing resistant starch improves markers of endothelial function with reduction of postprandial blood glucose and oxidative stress in patients with prediabetes or newly diagnosed type 2 diabetes. Atherosclerosis. 2012;224(2):457-464

60. Flammer AJ, Martin EA, Gossl M, et al. Polyphenol-rich cranberry juice has a neutral effect on endothelial function but decreases the fraction of osteocalcin-expressing endothelial progenitor cells. Eur J Nutr. 2013;52(1):289-296.

61. Widmer RJ, Freund MA, Flammer AJ, et al. Beneficial effects of polyphenol-rich olive oil in patients with early atherosclerosis. Eur J Nutr. 2013;52(3):1223-1231.

62. Tabit CE, Holbrook M, Shenouda SM, et al. Effect of sulfasalazine on inflammation and endothelial function in patients with established coronary artery disease. Vasc Med. 2012;17(2):101-107.

63. Flammer AJ, Hermann F, Wiesli P, et al. Effect of losartan, compared with atenolol, on endothelial function and oxidative stress in patients with type 2 diabetes and hypertension. J Hypertens. 2007;25(4):785-791.

64. Perlstein TS, Henry RR, Mather KJ, et al. Effect of angiotensin receptor blockade on insulin sensitivity and endothelial function in abdominally obese hypertensive patients with impaired fasting glucose. Clin Sci. 2012;122(4):193-202.

65. Modena MG, Bonetti L, Coppi F, Bursi F, Rossi R. Prognostic role of reversible endothelial dysfunction in hypertensive postmenopausal women. J Am Coll Cardiol. 2002;40(3):505-510.

66. Kitta Y, Obata JE, Nakamura T, et al. Persistent impairment of endothelial vasomotor function has a negative impact on outcome in patients with coronary artery disease. J Am Coll Cardiol. 2009;53(4):323-330. 


\section{Publish your work in this journal}

Vascular Health and Risk Management is an international, peerreviewed journal of therapeutics and risk management, focusing on concise rapid reporting of clinical studies on the processes involved in the maintenance of vascular health; the monitoring, prevention and treatment of vascular disease and its sequelae; and the involvement of

metabolic disorders, particularly diabetes. This journal is indexed on PubMed Central and MedLine. The manuscript management system is completely online and includes a very quick and fair peer-review system, which is all easy to use. Visit http://www.dovepress.com/ testimonials.php to read real quotes from published authors.

Submit your manuscript here: http://www.dovepress.com/vascular-health-and-risk-management-journal 